last part records the E.S.R. levels to be expected in a variety of diseases. It is clearly a work for specialists in rheumatic and other fields where the E.S.R. may be a valuable means of assessing progress or relapse, since it provides a proper understanding of a test often used in highly empirical fashion.

\section{The Preparation of Medical Literature}

Louise M. Cross, M.A. With a chapter on charts and graphs by Shirley Baty. Pp. xvi $+45 \mathrm{I}$, illustrated. London: Pitman Medical Publishing Co. 1960. 80s.

This book deals very clearly and fully with the techniques of writing medical literature in book and journal form. It is divided into seven sections. The first deals with the planning of a paper or book and in this connection the author gathered information from questionnaires sent to the editors of leading American journals asking their reasons for accepting and rejecting papers submitted to them. Prospective authors-take note!

This section is followed by one on gathering material for the paper or book and contains useful hints on collecting references, writing and arranging reference lists and bibliographies and on abstracting.

The third section deals with the actual writing of the paper and the fourth and fifth sections with style and styling. These last two sections are particularly useful, dealing as they do with the writing of good, clear English (style) and with problems such as when to use capitals, use of abbreviations and symbols, use of numbers and punctuation (styling). Styling will, of course, depend to a certain extent on the editorial policy of the publisher concerned, but general principles are usefully laid down.

The section on illustration explains techniques of preparing tables, charts and graphs, photographs, line drawings and colour illustrations and explains how blocks are made. This section should be very useful to the author, as it shows clearly how to prepare an illustration so that the best result will be obtained and stresses the importance of preliminary consultation with the publisher.

The last section deals with the editing of manuscripts by author and editor, with proof reading and with the preparation of indexes and revision for new editions.

This book was written for American readers, but there are only a few differences between American practice and that in this country. These are mainly concerned with copyright laws, differences in proof readers' marks and in abbreviations, and these are noted, together with a list of additional reference sources and books on printing techniques available to British readers, in a special section.

This book should be of equal value to both authors and their secretaries and to the editorial staff of publishers and is strongly recommended, not only for the completeness with which it covers its subject, but also for the clarity of its writing and the ease with which any point can be referred to-it is in itself a first-class examp!e of how to write a work of reference.

\section{Synovial Joints-their Structure and Mechanics}

C. H. Barnett, D. V. Davies and M. A. MaCConaill. Pp. $x i$ i +304 , illustrated. London: Longmans Green. 1961. 50s.

This book gives a comprehensive account of present knowledge of synovial joints. It is divided into four sections which separately cover the anatomy, the biology, the mechanics and the functions of joints. Each section can be read and understood separately. $\mathrm{Al}=$ though much information is compressed into quite small book, it is well put together and easy to read. Theo illustrations are adequate and the numerous references. are of value. Apart from pointing out many gaps in our knowledge, the authors do not hesitate to theorize ons? occasions; of particular interest are their views on the possible function of the ligamentum teres of the hip Pathological processes are only briefly mentioned.

This book can be safely recommended to all ortho- $-\frac{\bar{T}}{-}$ pædic surgeons: they will learn much from it and understand better the effect of disease, trauma and the surgeon's knife on synovial joints. Neoplastic Disease at Various Sites: Volume III,
Cancer of the Rectum
Editor: CUTHBERT E. DUKES, O.B.E., M.D., M.SC. $\frac{\rho}{\mathrm{\sigma}}$ F.R.c.s.; General Editor: D. W. SMITHERSo Pp. xiii +304 , illustrated. Edinburgh and Lon 3 . don: E. \& S. Livingstone. I960. 50s.

This is the third of a series of symposia on malignant disease conceived by Professor D. W. Smithers, and, since this volume has been edited by Dr. Cuthbert Dukes, no further recommendation may seem necessary It is, however, a remarkable book both in design and execution, setting forth all the known facts of the natural history, diagnosis, treatment and prognosis of rectal cancer.

The larger part of the contents is a distillation of thes unrivalled wisdom and experience of St. Mark's, but other contributors have more than pulled their weight $\vec{D}$ The statistical sections in particular are of an exceptiof standard for a surgical textbook; and those interestgd in the causes of rectal carcinoma will be intrigued by $\mathrm{f}^{-}$ chapter on comparative oncology.

Dr. Duke's reflections on causation and control characteristically modest, and nowhere is there a twe indication of the tremendous part which he has played in placing the treatment of this disease on such a sound basis.

Both from the practical and theoretical aspects, thisi book can be advised as excellent reading for post $\frac{0}{\Phi}$ graduate surgeons.

\section{Advances in Blood Grouping}

Alexander S. Wiener, M.D., F.A.C.P. Pp. 549 + xii. New York and London: Grune anđọ Stratton. I961. \$Ir.oo.

This volume is a collection of papers by A. S. Wiener and his collaborators reprinted in book form, the dates of original publication being mainly since 1953 , though a few are earlier, the earliest being dated 1946 .

Most of these are well known to blood serologists, but a few were first published in books or periodicals not generally available: of these the most interesting iso that written in collaboration with Wexler and published in 'Novant'anni delle Leggi Mendeliane' (Roma I956), which occupies pp. 44-6i of the present volume in the reviewer's opinion this is the most lucid and seductive exposition of Dr. Wiener's views on the structure of the $\mathrm{Rh}$ system which has yet been pub-N lished, and it contains an elegant account of possible mechanisms for cross-reactions.

Not many people will be inclined to buy this book for much of it has already been absorbed into the general knowledge of the blood serologist; but it is convenient for reference, and valuable because thes author's ideas are concentrated into one volume instead of being dissipated among several periodicals. 